\title{
Synthesis and in vitro Biodegradation of poly(ethylene adipate-co-D,L-lactic acid) Copolymers (PLEA)
}

\section{BAKOURI HICHEM, GUEMRA KADDOUR* and BOUKHOUYA IMENE}

Laboratory of Macromolecular Physical Organic Chemistry, Djillali Liabes University, BP89 City El Arbi Ben Mhidi Sidi Bel Abbes, Algeria.

${ }^{*}$ Correaponding author E-mail: guemra_2@yahoo.fr

http://dx.doi.org/10.13005/ojc/300318

(Received: June 03, 2014; Accepted: August 08, 2014)

\begin{abstract}
The present research mainly focused on the synthesis and study of biodegradation of poly (ethylene adipate-co-D,L-lactic acid). PLEA were prepared via ring opening polymerization from D,Llactide and poly(ethylene adipate). PLEA was characterized by ${ }^{1} \mathrm{H}$ NMR spectra and DSC; results showed that those properties showed high dependence on its composition.In vitro degradation behaviors of PLEA have been systematically investigated up to 12 weeks in phosphate buffer saline solution at $37^{\circ} \mathrm{C}$. The weight and polymer molecular weight were measured as a function of degradation time. Bacterial degradation was completed by investigating the physico-chemical properties using spectroscopy FTIR and DSC.
\end{abstract}

Key words: Ethylene adipate, D,L-Lactide, Biodegradation, Bacteria, physico-chemical properties.

\section{INTRODUCTION}

The synthesis routines of poly(lactic acid) (PLA) could be directly divided into polycondensation reaction from lactic acid and ring opening polymerization (ROP) from lactides, a coordinationinsertion mechanism has been proposed and widely accepted $^{1-2}$.

Microorganisms degrading PLA identified in literature are limited to Actinomycetes Amy- colatopsis type, and a bacterium, Bacillus Brevis. However, despite of the growing interests for its biomedical applications, many properties of PLA products still fall short of those required for some potential applications, due to its lackage of toughness and impact resistance ${ }^{3-5}$.

The poly(ethylene adipate) (PEA), exhibits excellent flexibility, whereas its mechanical strength is relatively poor and cannot meet various requirements due to its relatively low melting temperature $\left(60^{\circ} \mathrm{C}\right)^{6.7}$. 
Furthermore, as one of the most common aliphatic polyesters prepared from diacids and diols, PEA is also expected to be an economically competitive biodegradable polymer for its potent to be degraded and assimilated completely by microorganisms, as well as its low cost ${ }^{8-9}$.

Structural changes or composition modifications have been regarded as effective approaches to improve the properties of the polymers and promote its application to a much broader range $e^{4 \cdot 10.11}$.

Taking into consideration the difference in chain flexibility and physical properties between PLA and PEA, it seems of interest to prepare PLEA copolymer with hard PLA and soft PEA segments sharing the merits of PLA such as biocompatibility and biodegradability and PEA such as flexibility and thermal properties. Up to now, few related works have been reported on such a copolymer.

Moreover, taking into the consideration of excellent biodegradable performance of PLA and PEA, the PLEA copolymers are expected to be good alternatives for the non-degradable polymers in various applications.

In this article, we describe the synthesis of PLEA copolymers with various compositions, but the aim of this work was mainly dedicated to bacterial degradation of PLEA at $37^{\circ} \mathrm{C}$. Moreover, in vitro degradation behaviors of the sample in phosphate buffer saline solution (PBS) solution at $37^{\circ} \mathrm{C}$ were investigated in detail, with emphasis on change of the molecular weight, physico-chemical properties, weight and morphologies of sample during degradation.

\section{EXPERIMENTAL}

\section{Materials}

Adipic acid (AA) (p.a. Fluka), ethylene glycol (EG) (p.a. Fluka), D,L-lactide and stannous octoate were acquired from Aldrich. We investigated four different polymer formulations: PEA, PLEA75/25, PLEA55/45 and PDLLA. PLEA with lactic/ethylene adipate (LA/EA) molar ratio of 75/25 (PLEA75/25), 55/45 (PLEA55/45) and Poly(D,L-lactide) (PDLLA) were synthesized via ring opening polymerization.
Average molecular weights, melting and glass transition temperatures of these polyesters are shown in Table 1.

\section{Synthesis of hydroxyl terminated PEA}

PEA prepolymer was synthesized by a twostage preparation procedure, including esterification and polycondensation, AAand EG with a feeding molar ratio $1 / 2$ were added into the reactor, with 0.1 wt $\%$ stannous chlorides as catalyst. The reactor was evacuated and then filled with nitrogen for several times, in order to remove all of the oxygen. Then, the mixture was heated to $200{ }^{\circ} \mathrm{C}$ under stirring of $60 \mathrm{rpm}$ with reaction pressure of $0.35 \mathrm{MPa}$ for $4 \mathrm{~h}$ to eliminate the water generated.

The PEA prepolymer was removed, cooled, and milled. The PEA prepolymer was dissolved in chloroform and precipitated with methanol, then filtered and dried under vacuum at $40{ }^{\circ} \mathrm{C}$ to a constant weight for use.

\section{Synthesis of PLEA copolymers via ROP}

Different molar ratio of hydroxyl terminated PEA prepolymer and D, L-lactide mixed with stannous octoate (1wt\%) were added into a oneneck flask; after degassing, the flask was sealed under vacuum and the polymerization was proceeded at $120^{\circ} \mathrm{C}$ for $24 \mathrm{~h}$. The copolymers were dissolved in chloroform initially and then precipitated by adding excessive amount of cold methanol under stirring. Finally, the precipitants were filtered and washed by methanol, then dried under vacuum at $40{ }^{\circ} \mathrm{C}$ up to constant weight. The synthesis routine was shown in Figure 1.

\section{Microorganisms and Inoculums Preparation Bacteria}

The following bacterial strains cited in the ISO 846 standard $^{12}$ were used in the bio-degradation tests: Bacillus subtilis and Pseudomonas aeruginosa. These bacterial strains were supplied by the German DSMZ (Deutsche Sammlung von Mikroorganismen und Zellkulturen $\mathrm{GmbH}$ ) in lyophilized form and distributed separately in sterile glass tanks.

\section{Inoculums preparation}

At first, each bacterial strain was rehydrated separately. In a second step, a specific amount of hydrated fungus was inoculated into a solution 
composed of $250 \mathrm{ml}$ of basal liquid medium for bacteria which was incubated at $37^{\circ} \mathrm{C}$ during $72 \mathrm{~h}$.

The composition of the basal liquid medium for bacteria is: $1.0 \mathrm{~g}$ of $\mathrm{NH}_{4} \mathrm{NO}_{3} ; 0.7$ of $\mathrm{KH}_{2} \mathrm{PO}_{4} ; 0.3 \mathrm{~g}$ of $\mathrm{K}_{2} \mathrm{HPO}_{4} ; 0.5 \mathrm{~g}$ of $\left(\mathrm{MgSO}_{4}, 7 \mathrm{H}_{2} \mathrm{O}\right) ; 0.5 \mathrm{~g}$ of $\mathrm{NaCl}$; $0.01 \mathrm{~g}$ of $\left(\mathrm{FeSO}_{4}, 7 \mathrm{H}_{2} \mathrm{O}\right)$; and $1 \mathrm{~L}$ of distilled water. The $\mathrm{pH}$ was adjusted to $6-6.5$ by $\mathrm{NaOH}$ solution at $0.01 \mathrm{~mol} / \mathrm{L}$.

\section{Incomplete agar medium for the growth test}

Add to mineral salts solution, enough agars to obtain a concentration of $20 \mathrm{~g} / \mathrm{L}$. The mixture is boiled with stirring.

\section{Full agar medium for the bacteriostatic effect}

Add to incomplete agar medium, enough glucose to obtain a concentration of $30 \mathrm{~g} / \mathrm{L}$. Methods

\section{Biodegradation kinetics of PLEA}

All the experiment vessels and mineral media were sterilized by autoclaving at $121^{\circ} \mathrm{C}$ at a pressure of 1 bar for 20 min or by decontamination using a $0.5 \%$ sodium hypochlorite solution.

\section{Testing growth}

Samples polymers are seeded with a bacterial strain (Pseudomonas aeruginosa) in the presence of incomplete nutrient medium (free from carbon source). Bacterial growth can then be established at the expense of the polymer, in fact, if the polymer is not a nutrients of bacteria cannot grow $^{12}$.

\section{Bacteriostatic effects}

The sample is subjected to this time bacterial strain in the presence of a complete nutrient medium (with a carbon source). Even if the plastic contains no nutrients, bacteria can grow and metabolites can attack the material. The reaction medium is identical with the previous by the presence of glucose (at $30 \mathrm{~g} / \mathrm{L}$ ) as the carbon source.

\section{Hydrolytic Degradation Test}

Hydrolytic degradation experiments of copolyesters were carried out in a phosphate buffer solution (PBS, $\mathrm{pH}=7.4$ ) at $37^{\circ} \mathrm{C}$. The samples were stored in a thermostatical water bath for up to 12 weeks. At predetermined degradation time intervals, the samples were isolated from the medium, washed with purified water and then dried under vacuum at room temperature for $48 \mathrm{~h}$ before analysis.

\section{REULTS AND DISCUSSION}

\section{Chemical structure and compositions}

Figure 2a illustrates the ${ }^{1} \mathrm{H}$ NMR spectra of hydroxyl terminated PEA prepolymer synthesized via polycondensation reaction. The proton resonance signals arise at $\delta=1.64\left(\mathrm{H}^{2}\right), 2.34\left(\mathrm{H}^{1}\right), 3.72\left(\mathrm{H}^{6}\right)$, $3.82\left(\mathrm{H}^{4}\right), 4.21\left(\mathrm{H}^{5}\right)$, and $4.27 \mathrm{ppm}\left(\mathrm{H}^{3}\right)$, and the assignment of the signals is shown in accordance with the digital numbers marked in the structural formula of the PEA. Among the proton signals, $=3.72\left(\mathrm{H}^{6}\right), 3.82\left(\mathrm{H}^{4}\right), 4.21 \mathrm{ppm}\left(\mathrm{H}^{5}\right)$ were reasonably attributed to those protons in the end groups.

The relative integrity value of the methylene proton signals could be used to calculate the degree of polymerization $\left(D_{\mathrm{p}}\right)$ and number-average molecular weight $\left(M_{n, N M R}\right)$ of PEA prepolymer by using [4]:

Table 1: Molecular weight, melting temperature $\left(T_{m}\right)$ and glass transition temperature $\left(\mathrm{T}_{\mathrm{g}}\right)$ of the polyesters

\begin{tabular}{|c|c|c|c|c|c|}
\hline & \multicolumn{2}{|c|}{ Composition (\%) } & \multirow[t]{2}{*}{$\mathrm{T}_{\mathrm{g}}\left({ }^{\circ} \mathrm{C}\right)$} & \multirow[t]{2}{*}{$\mathrm{T}_{\mathrm{f}}\left({ }^{\circ} \mathrm{C}\right)$} & \multirow{2}{*}{$\begin{array}{c}M_{n} \\
\text { (g/mol) }\end{array}$} \\
\hline & EA & LA & & & \\
\hline PEA & 100 & 0 & -46 & 49 & 1278 \\
\hline PLEA1 & 45 & 55 & 40 & 159 & 9644 \\
\hline PLEA-2 & 25 & 75 & 45 & 190 & 15780 \\
\hline PLA & 0 & 100 & 62 & 300 & 32928 \\
\hline
\end{tabular}




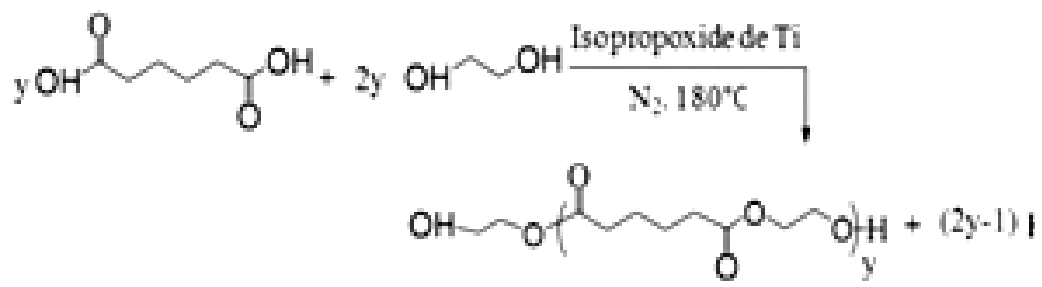

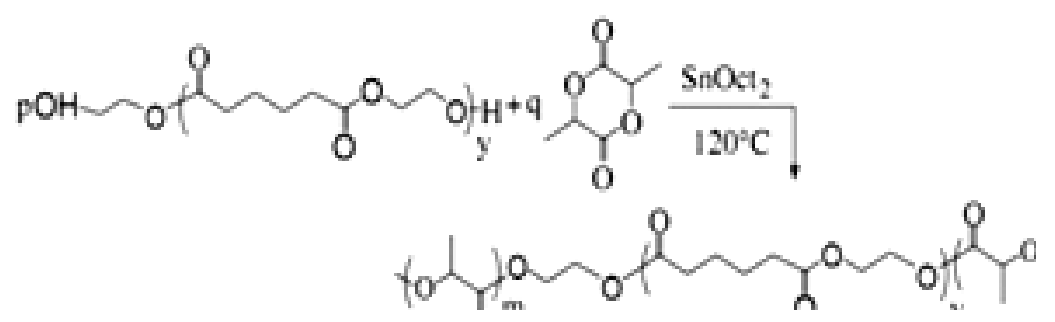

Fig. 1: Synthesis routine of PLEA copolymers

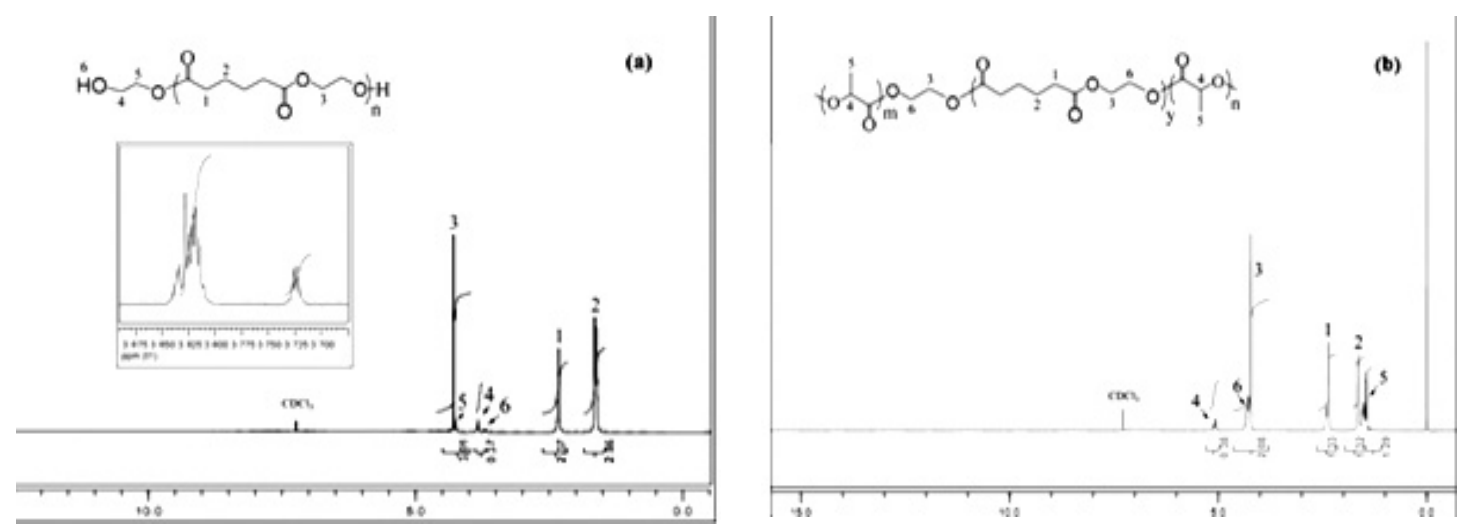

Fig. 2: 'H NMR spectra of PEA prepolymer (a), and PLEA copolymers (b)

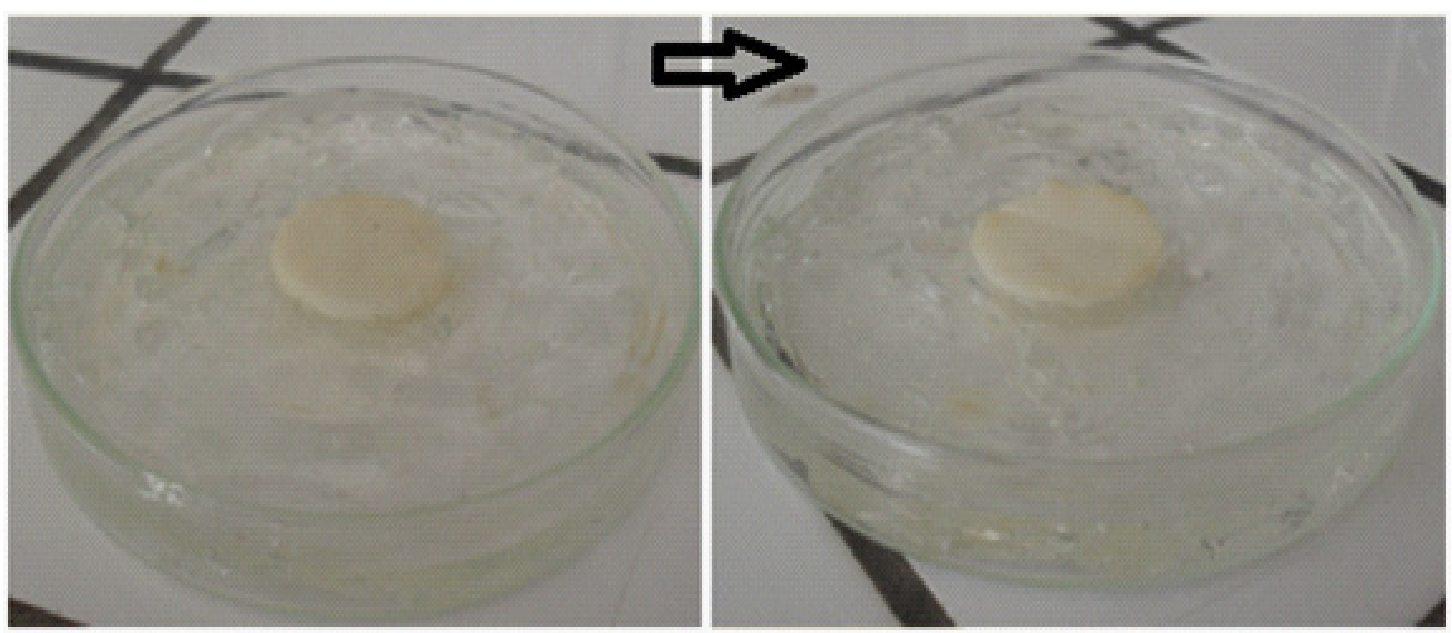

Fig. 3: Growth of a bacterial strain on samples PLEA in a poor medium at $37^{\circ} \mathrm{C}$ 


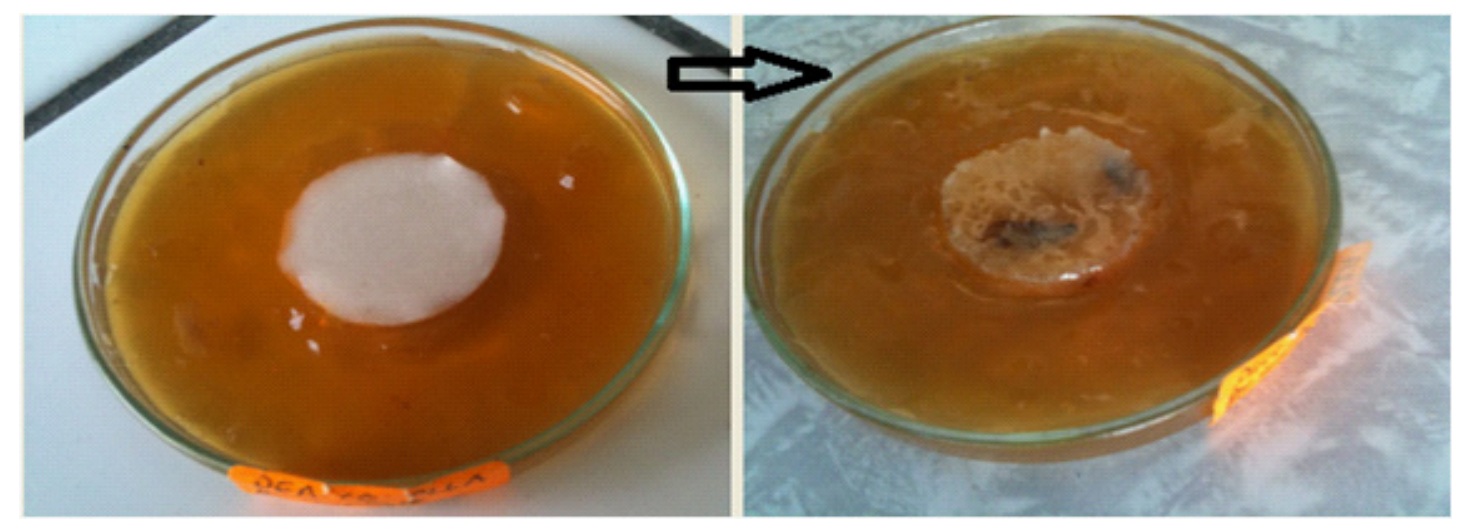

Fig. 4: Growth of a bacterial strain on samples PLEA in rich media at $37^{\circ} \mathrm{C}$

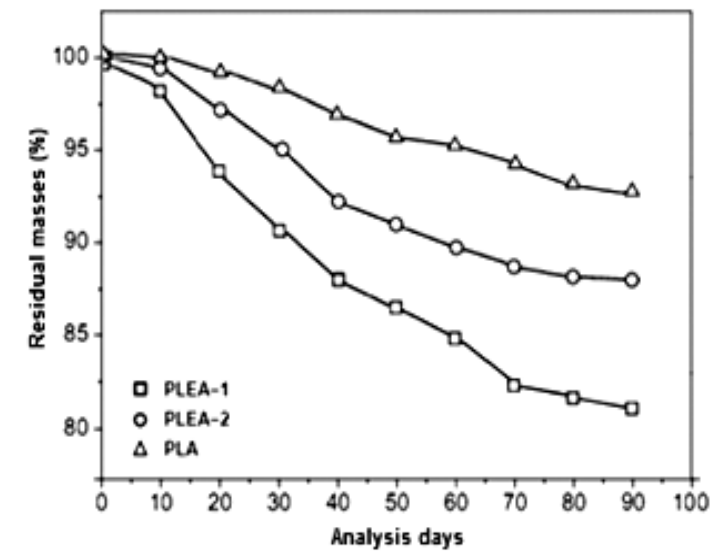

Fig. 6: Residual masses of PLEA-1, PLEA-2 and PLA after hydrolytic degradation in PBS

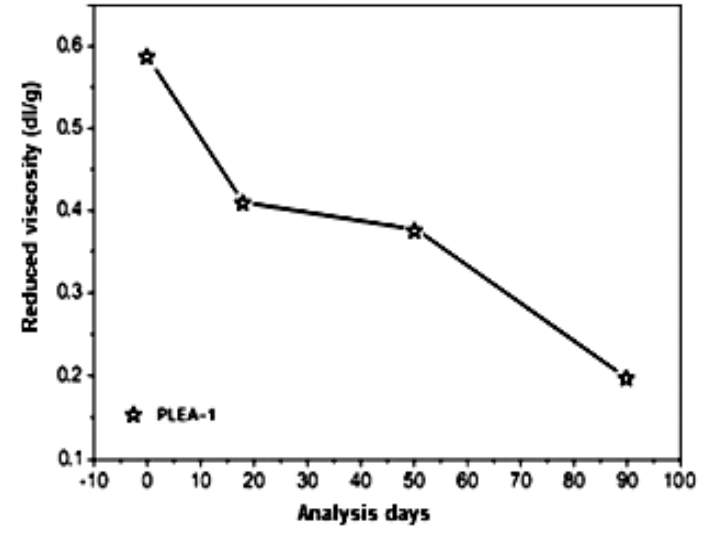

Fig. 7: Evolution of the reduced viscosity of PLEA-1 during the hydrolytic degradation

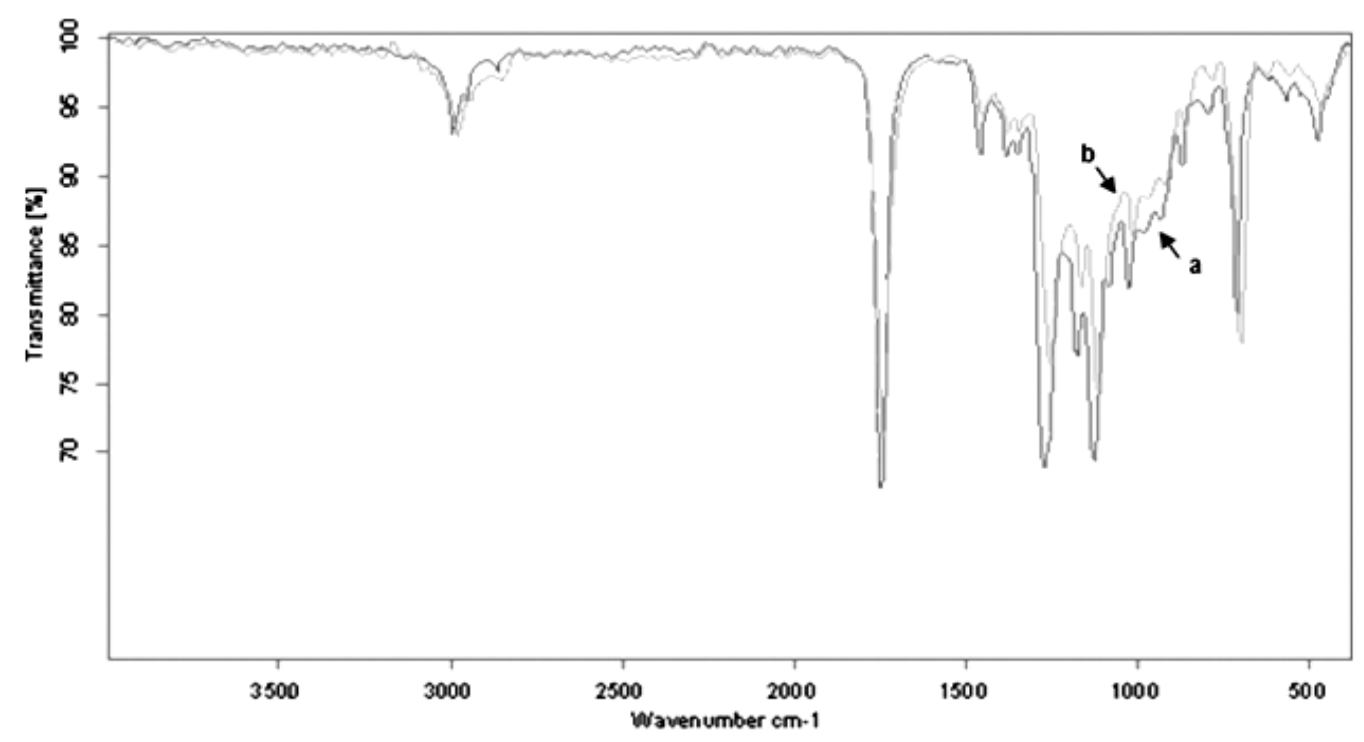

Fig. 8: FTIR spectra of PLEA initial (a) and after 90 days of degradation in abiotic media (b) 


$$
\begin{aligned}
& \mathrm{D}_{r}=\frac{\mathrm{J}_{3}}{\mathrm{~J}_{4}}+1 \\
& N_{\mathrm{HNWH}}=172 \times \mathrm{D}_{r}+2
\end{aligned}
$$

where $\mathrm{I}_{3}$ and $\mathrm{I}_{4}$ represent the intensity of methylene peak of EG located in the internal and end of PEA prepolymer's molecular chain, 172 and 2 the masses of repeating unit of EA segments and hydrogen atoms at the end of PEA prepolymer's molecular chain, respectively. The value of $M_{n, N M R}$ was $1278 \mathrm{~g} / \mathrm{mol}$, corresponding closely to $M_{\mathrm{n} \text {, viscosimetry }}$ $1319 \mathrm{~g} / \mathrm{mol}$.
Typical ${ }^{1} \mathrm{H}$ NMR spectrum of PLEA copolymers was illustrated in Figure $2 b$. It was found that all the intrinsic proton resonance signals for PEA and PLA homopolymers were all detected at chemical shifts of $=2.37\left(\mathrm{H}^{1}\right), 1.68\left(\mathrm{H}^{2}\right), 4.28 \mathrm{ppm}$ $\left(\mathrm{H}^{3}\right)$ for PEA, as well as $5.10\left(\mathrm{H}^{4}\right)$ and $1.52 \mathrm{ppm}\left(\mathrm{H}^{5}\right)$ for PLA, respectively. Moreover, other new signals were also found at chemical shifts at $=4.38\left(\mathrm{H}^{6}\right)$, the assignment of which was marked in the sequence structure of PLEA copolymer in.

\section{The bacteriostatic effect}

The visual examination of the samples of polymers exposed to a bacterial suspension in

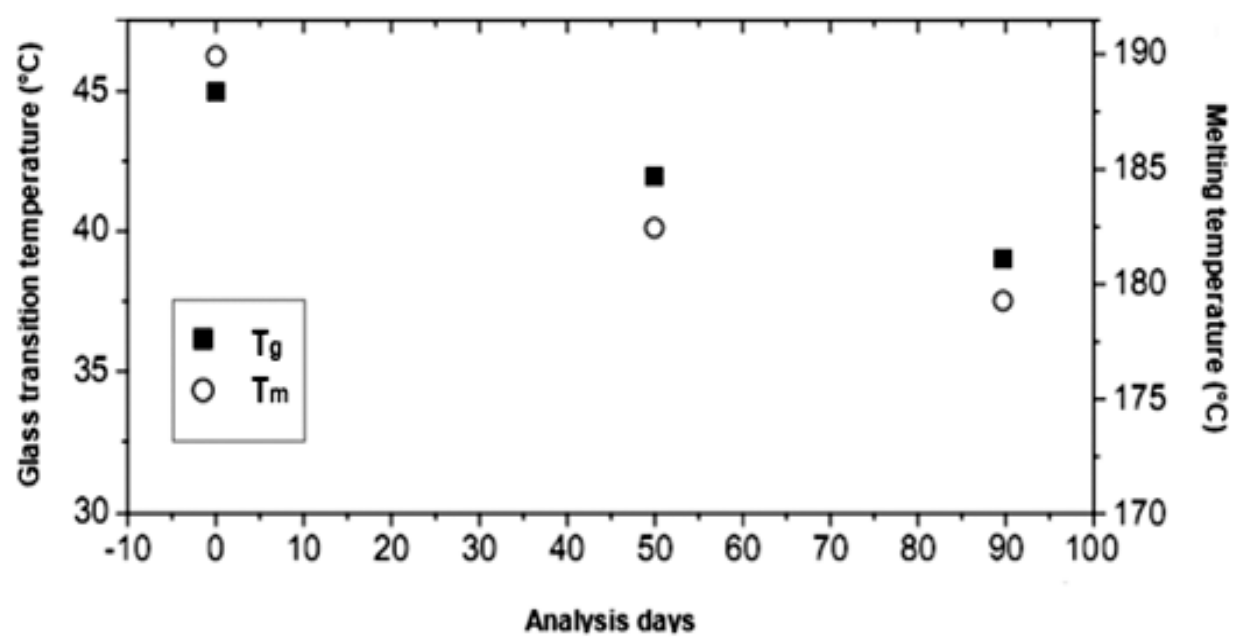

Fig. 9: Evolution of the thermal properties of PLEA during its bacterial degradation

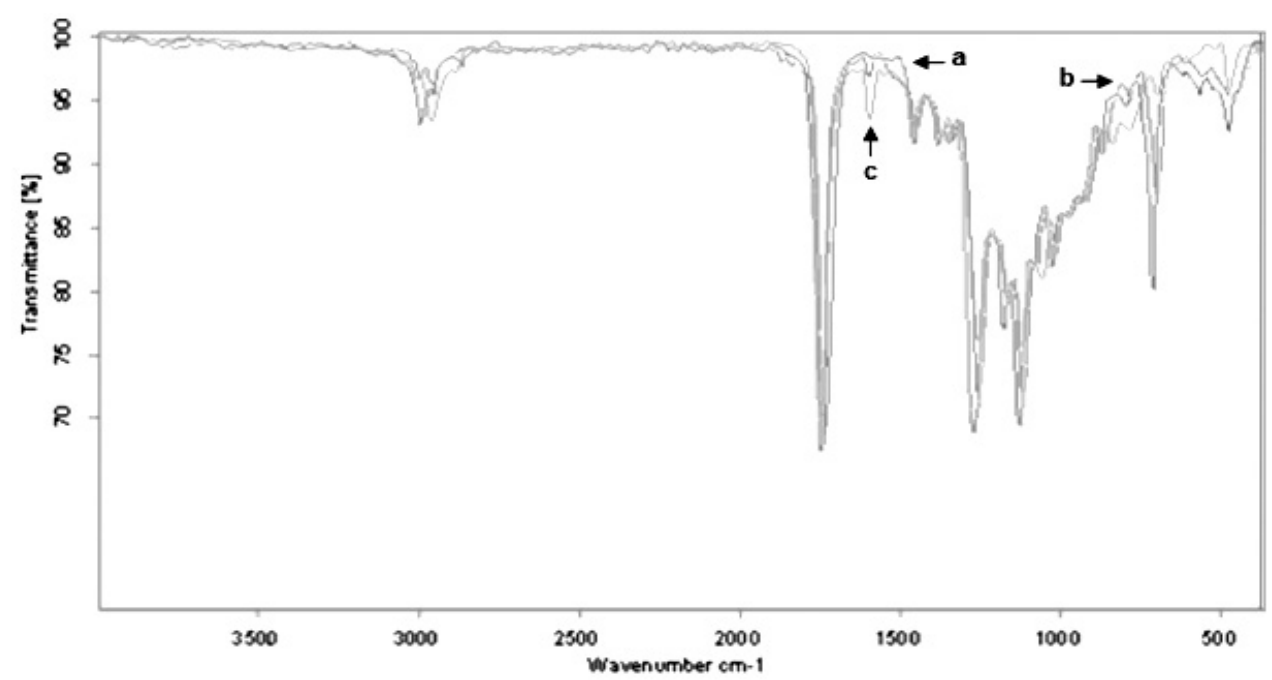

Fig. 10: FTIR spectra of PLEA initial (a), after 50 days (b) and 90 days (c) of degradation in biotic media 
complete medium (Figure 4) demonstrates a strong visible to the naked eye bacterialgrowth. So there total lack of bacteriostatic effect for PLEA, it does not inhibit the growth of bacteria metabolizing glucose. The copolymer apparently is not causing toxicity towards bacteria.

\section{Evolution of physico-chemical properties}

Two types of mixtures were prepared for this test to distinguish the purely bacterial degradation and chemical hydrolysis. The biodegradation tests were performed in a biotic medium (polymer inoculated by bacteria), and also in an abiotic medium (not inoculated by bacteria) to investigate the effect of the hydrolysis degradation. In a biotic medium, aprocess of biodegradation can occur; in an abiotic one, only chemical hydrolysis can happen.

At predetermined time intervals of degradation residues visible samples, are isolated periodically clamp undergoes various washings with water, dried in a desiccators at room temperature for $48 \mathrm{~h}$ and then weighed to determine the weight loss and the reduced viscosity of the sample, characterization by DSC and FTIR spectroscopy were determined at the same time intervals.

\section{Test hydrolytic degradation "abiotic medium»}

The degradation characteristics of the copolymers (PLEA-1, PLEA-2) were evaluated by measuring the weight loss and decrease in reduced viscosity. For this purpose, the copolymer is preweighed and then placed in $25 \mathrm{ml}$ of PBS pH 7.4 at $37^{\circ} \mathrm{C}$.Phosphate Buffer Solution (PBS) was prepared by dissolving the mixture of $\mathrm{KH}_{2} \mathrm{PO}_{4}(4.710 \mathrm{~g})$ and $\mathrm{Na}_{2} \mathrm{HPO}_{4}(19,778 \mathrm{~g})$ in $1 \mathrm{~L}$ of sterile distilled water.

\section{Evolution of the residual mass}

Changes in the molecular weight and the mass of the samples were monitored throughout the process of hydrolytic degradation. The effects of hydrolytic degradation are measured and expressed as a variation of the residual mass as a function of time in Figure 5.

Fig. 5: Residual masses of PLEA-1, PLEA-2 and PLA after hydrolytic degradation in PBS

Moreover, the results also indicated that the degradation rate of the copolymer increases with increasing PEA content. This phenomenon has been attributed to the morphology of the copolymers. The copolymer with PLA Iow (PLEA-1) was amorphous and water easily penetrated the mass of the copolymer, so that the rate of degradation of the samples was fast, but in the PLA alone, the water was difficult to into the polymer as it is semicrystalline and the rate of degradation of the samples was low.

\section{Evolution of the reduced viscosity of PLEA}

Figure 6 shows a drastic decrease of the reduced viscosity in abiotic medium during the first 17 days.

\section{Infrared analyses}

Figure 7 shows the FTIR spectra in the attenuated total reflection mode of PLEA at its initial state $(\mathrm{t}=0)$ and after 90 days of degradation in abiotic media. Peak positions and assignments for PLEA initial are: $v(-\mathrm{CH}-)$ stretch at 2,997 and 2,985 $\mathrm{cm}^{-1}$; carbonyl ester $(\mathrm{C}=\mathrm{O})$ at $1,759 \mathrm{~cm}^{-1}, \delta(-\mathrm{CH}-)$ deformation at 1,383 and $1,365 \mathrm{~cm}^{-1}, v(-\mathrm{C}-\mathrm{O}-)$ stretch at 1,186, 1,134, 1,091 and stretch $v(-\mathrm{C}-\mathrm{C}-)$ at $870 \mathrm{~cm}^{-1}$.

Several changes are observed in the thermal properties of PLEA during the biodegradation process: decreases of $\mathrm{T}_{\mathrm{g}}$ from 44.9 to $39.2^{\circ} \mathrm{C}$ and that of $T_{m}$ from 190.2 to $163.7^{\circ} \mathrm{C}$ between the beginning of the test and the day 90 . The fact that $T_{g}$ decreased indicates that the PLEA undergone a physical degradation throughout the experiment conducted. The occurred damage in the amorphous phase and the formation of low molecular weight fragments, which are easily crystallized, lead to an increase of the degree of crystallinity in the earliest days of the biodegradation. Then, this percentage crystallinity starts later to decrease which means that the crystalline regions start to be damaged because of the bioassimilation of the small fragments by the microorganisms. Gattin and al. [16] had investigated on the biodegradation of a polylactic acid-based material by microorganisms in a liquid medium. They found the $T_{g}$ values decreased strongly throughout the experiment of biodegradation and with increasing time, the extent of the degradation was characterized by simultaneous decreases of $T_{g}$ and percentage crystallinity. 


\section{Infrared Analyses}

PLEA fragments, recovered after 50 and 90 days in biotic mediums were analyzed by FTIR (Figure 9).Spectra comparison before and after degradation showed the formation of a new band at $1,600 \mathrm{~cm}^{-1}$ that corresponds to carboxylate ions in the spectrum of the biotic media. The appearance of carboxylate ions at the $1,600 \mathrm{~cm}^{-1}$ position is due to microorganisms which consume lactic acid and its oligomers on the surface and leave carboxylate ions at the chain end ${ }^{17}$.

Fig. 10: FTIR spectra of PLEA initial (a), after 50 days (b) and 90 days (c) of degradation in biotic media

The first step in the biodegradation is a chemical hydrolysis in the middle of the polymer chain with the oligomer in the migration medium; the second stage corresponds to a bacterial mineralization at the ends of strings. The PLEA therefore undergoes a profound change in its chemical structure activity precedes significant mineralization (chemical hydrolysis and bioassimilation are not simultaneous).

A series of PLEA copolymers with various compositions was synthesized from hydroxyl terminated PEA prepolymer and D,L-lactide with stannous octoate $\left(\mathrm{SnOct}_{2}\right)$ as catalyst via ROP.
DSC analysis demonstrated that the crystal structures in PLEA copolymers were dominated by LA segments, while EA segments remained amorphous due to the existence of ester exchange reaction during the polymerization process. Moreover, $\mathrm{T}_{\mathrm{m}}$ and $\mathrm{T}_{\mathrm{g}}$ increased with less $\mathrm{EA}$ segments incorporated into the PLEA.

The evaluation of the ability of bacteria to use a polymer as a carbon source has been demonstrate by testing growth on solid media, performed at $37^{\circ} \mathrm{C}$, show that the conformations adopted by the polymer seem more accessible to enzymes microorganisms.

After defining the bacteria degrading copolymer, monitoring changes in the physicochemical properties of the polymer during the degradation and the time was made.

In the case of PLEA, at the beginning the monomers and monoesters (formed by hydrolysis) are bioassimilated by microorganisms then a long hydrolysis of ester bands occurs due to the temperature and the humidity, then the oligomer fragments formed by extended hydrolysis are bioassimilated by microorganisms. During these two steps, hydrolysis and bioassimilation, both molecular weights and glass transition decrease (degradation happens at the level of ester bonds and at chainends).

\section{REFERENCES}

1. Garlotta, D. A., literature review of poly (lactic acid).J. Polym. Environ., 2001; 9(2): 63-84.

2. Li, B.; Chen, S.C.; Qiu, Z.C.;et al.,Synthesis of poly(lactic acid-b-p-dioxanone) block copolymers from ring opening polymerization of p-dioxanone by poly(L-lactic acid) macroinitiators. Polym. Bull., 2008; 61(2): 139-146.

3. Mehta, R.; Kumar, V.; Bhunia, H.; Upadhyay, S.N.,Synthesis of poly (lactic acid): a review. J. Macromol. Sci. Polym. Rev., 2005; 45(4): 325-349 (2005)

4. Zeng, J.B.; Li, Y.D.; Zhu, Q.Y.;et al.,A novel biodegradable multiblock poly (ester urethane) containing poly (L-lactic acid) and poly (butylene succinate) blocks. Polymer., 2009;
50(5): 1178-1186.

5. Ba, C.Y.; Yang, J.; Hao, Q.H.; et al.,Syntheses and physical characterization of new aliphatic triblock poly (L-lactide-b-butylene succinate-bL-lactide)s bearing soft and hard biodegradable building blocks. Biomacromolecules.,2003; 4(6):1827-1834.

6. Kim, S.W.; Lim, J.C.; Kim, D.J.; Seo, K.H.,Synthesis and characteristics of biodegradable copolyesters from the transesterification of poly (butylene adipate-co-succinate) and poly (ethylene terephthalate). J. Appl. Polym. Sci., 2004; 92(5): 3266-3274.

7. Monvisade, P.; Loungvanidprapa, P., Synthesis of poly (ethylene adipate) and poly (ethylene 
adipate-co-terephthalate) via ring-opening polymerization. Eur. Polym. J., 2007; 43: 3408-3414.

8. Atkins, T.W.,Biodegradation of poly (ethylene adipate) microcapsules in physiological media. Biomaterials.,1998; 19(1-3): 61-67.

9. Kim, M.N.; Kim, K.H.; Jin, H.J.;et al., Biodegradability of ethyl and n-octyl branched poly (ethylene adipate) and poly (butylene succinate). Eur. Polym. J., 2001; 37(9):18431847.

10. Kramer, J.W.; Treitler, D.S.; Dunn, E.W.; et al.,Polymerization of enantiopure monomers using syndiospecific catalysts: a new approach to sequence control in polymer synthesis. J. Am. Chem. Soc., 2009; 131(44): 16042-16044.

11. Pfeifer, S.; Lutz, J.F.,A facile procedure for controlling monomer sequence distribution in radical chain polymerizations. J. Am. Chem. Soc.,2007; 129(31): 9542-9543.

12. ISO 846 , Plastics-evaluation of the action of microorganisms. International Organization for Standardization, Geneva 1997

13. Deng, L.M.; Wang, Y.Z.; Yang, K.K.; et al., A new biodegradable copolyester poly (butylene succinate-co-ethylene succinateco-ethylene terephthalate). Acta. Mater., 2004; 52(20):5871-5878.

14. Hakkarainen, M.; Karlsson, S.; Albertsson, A.C.,Polymer.,2000; 41:2331.

15. Khabbaz, F.; Karlsson, S.; Albertsson, A.C.,J. Appl. Polym. Sci.,2000; 78: 2369.

16. Gattin, R.; and al., Comparative biodegradation study of starch- and polylactic acid-based materials. Journal of Polymers and the Environment., 2001; 9(1): p. 11-17

17. Khabbaz, F.; Karlsson, S and Albertsson, A.C., Py-GC/MS an effective technique to characterizing of degradation mechanism of poly (L-lactide) in the different environment. Journal of Applied Polymer Science.,2000, 78(13): p. 2369-2378. 